\title{
Drug utilization pattern of antihypertensive drugs in chronic kidney disease stage 5 patients in a tertiary care hospital of central India
}

\author{
Kalpana Bharani $^{1 *}$, Rajesh Bharani², Rubina Vohra ${ }^{3}$, Chhaya Goyal ${ }^{1}$
}

${ }^{1}$ Department of Pharmacology, Sri Aurobindo Medical College and Postgraduate Institute, Indore, Madhya Pradesh, India ${ }^{2}$ Department of Nephrology, Bombay Hospital, Indore, Madhya Pradesh, India ${ }^{3}$ Department of Nephrology, Sri Aurobindo Medical College and Postgraduate Institute, Indore, Madhya Pradesh, India

Received: 15 May 2018 Accepted: 04 June 2018

*Correspondence to: Dr. Kalpana Bharani, Email: drkalpanabharani@ gmail.com

Copyright: (C) the author(s), publisher and licensee Medip Academy. This is an openaccess article distributed under the terms of the Creative Commons Attribution NonCommercial License, which permits unrestricted noncommercial use, distribution, and reproduction in any medium, provided the original work is properly cited.

\begin{abstract}
Background: India is experiencing a rapid health transition and is projected to become a major reservoir of chronic diseases like Diabetes and Hypertension and 25 to $40 \%$ of these subjects may develop chronic kidney disease and end stage renal disease. Aim and objective of the study was to analyze utilization pattern of antihypertensive drugs in chronic kidney disease patients in a tertiary care hospital.

Methods: The present observational cross-sectional study was conducted in Sri Aurobindo Institute of Medical Sciences, Indore (M.P.) from 01.01.2018 to 31.03.2018 on patients with chronic kidney disease stage 5. The drug utilization pattern was studied with respect to age, sex, basic disease, duration of dialysis, type of antihypertensive used, etc. Comparison of mean between gender and dialysis / not on dialysis was done using unpaired ' $t$ ' test. A p value of $<0.05$ was taken as statistically significant.

Results: Of 198 patients, 63 (31.8\%) were females and $135(68.2 \%)$ were males, showing a male preponderance. Majority of the patients $(54 \%)$ belonged to the age group 41-60 years. Majority of the patients were having diabetic nephropathy (40.9\%), followed by CGN-CKD 5d (18.7\%) and CIN-CKD 5d (17.2\%). 11.6\% patients were not on dialysis, while $88.4 \%$ were on dialysis with a mean duration of dialysis of $31.45 \pm 34.57$ months. Calcium channel blockers were given in $87.4 \%$ patients, followed by centrally acting drugs in $56.1 \%$ patients, beta blockers in $51.0 \%$ and alpha blockers in $39.9 \% .93 .9 \%$ patients were on multidrug antihypertensive therapy. Mean number of antihypertensives required in patients on dialysis was lower than those not on dialysis $(2.69 \pm 1.44$ vs. $3.48 \pm 1.16$, p $<0.05)$, similarly mean number of antihypertensives use in males was higher than females $(2.99 \pm 1.41$ vs. $2.32 \pm 1.37$, p <0.05).

Conclusions: In order to treat CKD, it is important to treat hypertension as hypertension and CKD are related to each other. Treatment of hypertension will help in controlling future development of comorbidities. Calcium channel blockers and centrally acting drugs are the treatment of choice in patients with CKD stage 5D with hypertension. Multi-drug antihypertensive therapy is a better choice than mono/single-drug antihypertensive therapy.
\end{abstract}

Keywords: Antihypertensive use, Chronic kidney disease, End stage renal disease, Hemodialysis, Hypertension

\section{INTRODUCTION}

Hypertension is the most common modifiable risk factor for cardiovascular diseases (CVD), stroke and renal failure. ${ }^{1}$ It is the second leading cause of chronic kidney disease (CKD). It is estimated that more than one billion adults are hypertensive worldwide and this figure is projected to increase to 1.56 billion by the year 2025 , which is an increase of $60 \%$ from 2000. Cardiovascular diseases and Hypertension are accounting for loss of $4 \%$ 
gross domestic product for low and middle-income countries annually which is amounting 500 billion USD. ${ }^{2}$ Clinical evidence suggests that lowering blood pressure (BP) with antihypertensive drugs reduces the risk of myocardial infarction, stroke, heart failure, revascularization procedures and end-stage renal diseases in hypertensive patients. ${ }^{3}$

The increasing prevalence of hypertension has been attributed to population growth, ageing and behavioral risk factors, such as unhealthy diet, excess use of alcohol, sedentary lifestyle, obesity, and exposure to persistent stress. A whopping 9.4 million deaths occur worldwide every year because of hypertension, with it being responsible for about $50 \%$ of mortality due to heart disease and stroke. ${ }^{4,5}$ Epidemiological studies demonstrated that prevalence of hypertension is increasing rapidly in India, varying from 4 to $15 \%$ in urban and $2-8 \%$ in rural population. ${ }^{6,7}$

Several guidelines have been developed worldwide for the management of hypertension, and these serve as reference standards for clinical practitioners. However, many clinicians practice their own prescribing pattern in treating hypertensive patients according to their clinical experience. Primary care physicians need to be empowered in appropriate and evidence-based management of hypertension. A review of these prescribing patterns and guideline-based use of antihypertensive medications can give better insights into the concept of personalised, yet cost-effective pharmacological management of hypertension.

Aim of the study was to analyze utilization pattern of antihypertensive drugs in chronic kidney disease patients in a tertiary care hospital.

\section{METHODS}

The present observational cross-sectional study was conducted in Sri Aurobindo Institute of Medical Sciences, Indore (M.P.) from $1^{\text {st }}$ January 2018 to $31^{\text {st }}$ Match 2018 on patients with chronic kidney disease stage 5 presenting to institution during the study period.

A customized proforma was designed for collecting the information for the study. Before enrolling the patient into the study, a detailed information about the study, its procedures, risks/benefits, etc. were explained to them and after obtaining their voluntary written informed consent for participation, the data from the records of the patients were looked into and their demographic details and antihypertensives drugs prescribed were collected.

The data was then entered into the Microsoft Excel for analysis and online statistical software were used for calculating the $\mathrm{p}$ values.

A total of 198 patients were included in the study.

\section{Inclusion criteria}

- All patients diagnosed to have chronic renal disease stage 5, undergoing treatment in Nephrology unit of this hospital ward

- Patients and/or his/her legally acceptable representatives willing to provide their voluntary written informed consent for participation in the study

\section{Exclusion criteria}

- Children, pregnant and lactating women, surgical conditions like kidney stone, tumors and trauma

- Patients and/or his/her legally acceptable representatives not willing to provide their voluntary written informed consent for participation in the study.

A written permission has been obtained from the Institutional Ethics Committee for the conduct of the study in this institution. The present study is a non-interventional study and does not involve any procedures / tests. Only data from the records of the patients were collected and also written informed consent form was obtained from the patients for allowing the researchers to look into the medical records. All the personal data of the patients was kept confidential and only data was used for research purpose.

\section{RESULTS}

In the present study there were 198 patients, of which 63 $(31.8 \%)$ were females and $135(68.2 \%)$ were males, showing a male preponderance of chronic kidney disease in this study in comparison to the women. Majority of the patients belonged to the age group 41-60 years - 107 $(54.0 \%)$, followed by $48(24.2 \%)$ patients of age group 6180 years and $37(18.7 \%)$ patients of age group 21-40 years.

There were $8.1 \%$ patients with ADPKD (Autosomal Dominant Polycystic Kidney Disease), $18.7 \%$ patients were having CGN-CKD 5d, $17.2 \%$ patients were having CIN-CKD 5d, $40.9 \%$ patients were having diabetic nephropathy, $9.1 \%$ patients were having hypertensive nephropathy, $2.5 \%$ patients were having obstructive uropathy and $3.5 \%$ patients were having SLE - lupus nephritis (Table 1).

Of the 198 patients, $23(11.6 \%)$ patients were not on dialysis, while the rest were on hemodialysis. In $24.2 \%$ patients the duration of dialysis was 1-6 months, in 11.1\% patients it was 6-12 months, in $15.2 \%$ patients it was 13 24 months, in $24.7 \%$ patients it was $25-60$ months and in $13.1 \%$ patients it was $>60$ months. Majority of them had $24.7 \%$ patients had duration between 25-60 months with a mean duration of dialysis of $31.45 \pm 34.57$ months (Table 2). 
Table 1: Distribution of patients according to basic disease.

\begin{tabular}{|lll|}
\hline Basic disease & Number & Percentage \\
\hline ADPKD & 16 & 8.1 \\
\hline CGN-CKD 5d & 37 & 18.7 \\
\hline CIN-CKD 5d & 34 & 17.2 \\
\hline Diabetic nephropathy & 81 & 40.9 \\
\hline Hypertensive nephropathy & 18 & 9.1 \\
\hline Obstructive uropathy & 5 & 2.5 \\
\hline SLE - Lupus Nephritis & 7 & 3.5 \\
\hline Total & 198 & 100.0 \\
\hline
\end{tabular}

Table 2: Distribution of patients according to duration of dialysis.

\begin{tabular}{|lll|}
\hline Duration of dialysis & Number & Percentage \\
\hline 1-6 months & 48 & 24.2 \\
\hline 6-12 months & 22 & 11.1 \\
\hline 13-24 months & 30 & 15.2 \\
\hline $25-60$ months & 49 & 24.7 \\
\hline$>60$ months & 26 & 13.1 \\
\hline Not on dialysis & 23 & 11.6 \\
\hline Total & 198 & 100.0 \\
\hline
\end{tabular}

Table 3: Distribution according to various types of antihypertensives.

\begin{tabular}{|lll|}
\hline \multicolumn{2}{l}{ Number } & Percentage \\
\hline Calcium channel blockers & & \\
\hline Nifedipine & 81 & 40.9 \\
\hline Amlodepin & 66 & 33.3 \\
\hline Cilnidepin & 26 & 13.1 \\
\hline Beta blockers & & \\
\hline Metoprolol & 60 & 30.3 \\
\hline Atenolol & 14 & 7.1 \\
\hline Carvedelol & 27 & 13.6 \\
\hline Others & 0 & 0.0 \\
\hline ATRB & & \\
\hline Losartan & 5 & 2.5 \\
\hline Telmisartan & 16 & 8.1 \\
\hline Olmesartan & 3 & 1.5 \\
\hline Others & 0 & 0.0 \\
\hline ACE inhibitors & & \\
\hline Ramipril & 3 & 1.5 \\
\hline Enalapril & 0 & 0.0 \\
\hline Others & 0 & 0.0 \\
\hline Centrally Acting Drugs & & \\
\hline Clonidine & 65 & 32.8 \\
\hline Maxonidine & 36 & 18.2 \\
\hline Minoxidil & 10 & 5.1 \\
\hline Alpha Blockers & 76 & 38.4 \\
\hline Prazocin & 3 & 1.5 \\
\hline Doxazocin &
\end{tabular}

The calcium channel blockers viz. Nifedipine was used in $40.9 \%$ patients, Amlodepin in $33.3 \%$ patients and Cilnidepin in $13.1 \%$ patients. Beta blockers viz.
Metoprolol was used in $30.3 \%$ patients, Atenolol in $7.1 \%$ patients and Carvedilol in 13.6\%. ATRB viz. Losartan was used in $2.5 \%$ patients, Telmisartan in $8.1 \%$ patients and Olmesartan in $1.5 \%$ patients. ACE inhibitors viz. Ramipril was used in $1.5 \%$ patients. Centrally acting drugs viz. Clonidine was used in $32.8 \%$ patients, Maxonidine in $18.2 \%$ patients and Minoxidil in $5.1 \%$ patients. Alpha blockers viz. Prazocin was used in $38.4 \%$, Doxazocin in $1.5 \%$ patients. Diuretics viz. Furasemide in $7.1 \%$ patients, Torsemide in $16.2 \%$ patients and Metalazone in $6.6 \%$ patients (Table 3).

In $6.1 \%$ patients no antihypertensives were used, in $66.2 \%$ patients 1-3 antihypertensives were used, in $24.2 \%$ patients 4-5 antihypertensives were used and in 3.5\% patients more than 5 antihypertensives were used. Majority of the patients were on 1-3 antihypertensives.

The mean number of antihypertensives required in patients on dialysis was $2.69 \pm 1.44$, while number of antihypertensives required in patients not on dialysis was $3.48 \pm 1.16$. The difference was found to be statistically significant $(\mathrm{P}<0.05)$, showing that more number of antihypertensives are required for patients not on dialysis in comparison to the patients on dialysis (Table 4).

Table 4: Comparison of mean number of antihypertensives between dialysis and non-dialysis patients.

\begin{tabular}{|lllll|}
\hline Dialysis & No. & Mean \pm SD & ' $t$ ' Value & P value \\
\hline $\begin{array}{l}\text { On } \\
\text { dialysis }\end{array}$ & 175 & $2.69 \pm 1.44$ & $\begin{array}{l}-2.535, \\
\text { df=196 }\end{array}$ & $0.012 *$ \\
\cline { 1 - 2 } Not on & 23 & $3.48 \pm 1.16$ & & \\
\hline dialysis & 23 & & \\
\hline
\end{tabular}

Unpaired ' $\mathrm{t}$ ' test applied. $\mathrm{P}$ value $=0.012$ Significant

The mean number of antihypertensives required in males was $2.99 \pm 1.41$, while number of antihypertensives required in females was $2.32 \pm 1.37$. The difference was found to be statistically significant $(\mathrm{P}<0.05)$, showing more number of antihypertensives requirement in males in comparison to the females (Table 5).

Table 5: Comparison of mean number of antihypertensives in relation to gender.

\begin{tabular}{|c|c|c|c|c|}
\hline Gender & No. & Mean \pm SD & 't' Value & P value \\
\hline Male & 135 & $2.99 \pm 1.41$ & \multirow{2}{*}{$\begin{array}{l}3.167 \\
d f=196\end{array}$} & \multirow{2}{*}{$0.002 *$} \\
\hline Female & 63 & $2.32 \pm 1.37$ & & \\
\hline
\end{tabular}

Unpaired ' $\mathrm{t}$ ' test applied. $\mathrm{P}$ value $=0.002$ Significant

\section{DISCUSSION}

In the present study 198 patients were enrolled. There was a male preponderance in this study with corresponds to results published by Joseph et al, who also reported a higher incidence of hypertension in males in comparison to the females. ${ }^{8}$ 
Majority of the patients were having diabetic nephropathy, followed by CGN-CKD 5d and CIN-CKD 5d.

Higher number of the patients with hypertension belonged to the age group 41-60 years, which is similar to that reported by Saju et al, who reported an incidence of $33 \%$ in the age group 51-60 years. ${ }^{9}$

Only $23(11.6 \%)$ patients were not on dialysis, while the rest majority of the patients $175(88.4 \%)$ were on dialysis, with $24.7 \%$ patients having duration between 25-60 months with a mean duration of dialysis of $31.45 \pm 34.57$ months.

In the present study, calcium channel blockers were given in majority of the patients $(87.4 \%)$, followed by centrally acting drugs in $56.1 \%$ patients, beta blockers in $51.0 \%$, alpha blockers in $39.9 \%$, ARTB in $12.1 \%$ patients and ACE inhibitors in $1.5 \%$ patients. Study done by Bhanu et al, also reported calcium channel blockers to be the most commonly prescribed antihypertensives (39.5\%), followed by diuretics $(25.1 \%)$. Saju et al, also reported an $70 \%$ use of calcium channel blockers in their study. ${ }^{9,10}$

In the present study most of the patients (93.9\%) were treated with multi-drug antihypertensive therapy, while no antihypertensive was given in $6.1 \%$ patients. Study done by Elhami et al, also reported similar trend $-50 \%$ on two drug therapy and $20 \%$ on three drug therapy. ${ }^{11}$ Higher number of antihypertensives use was seen in patients not on dialysis in comparison to the lower number of antihypertensives use in patients on dialysis $(\mathrm{p}<0.05)$.

In this study we found that the mean number of antihypertensive requirement in the males was higher in comparison to the females $(\mathrm{p}<0.05)$.

\section{CONCLUSION}

In order to treat $\mathrm{CKD}$, it is important to treat hypertension as hypertension and CKD are related to each other. Treatment of hypertension will help in controlling future development of comorbidities. Calcium channel blockers and centrally acting drugs are the treatment of choice in patients with CKD stage 5D with hypertension. Multi-drug antihypertensive therapy is a better choice than mono/single-drug antihypertensive therapy. Patients who are on dialysis and females require lesser number of antihypertensives than those patients not on dialysis.

\section{ACKNOWLEDGEMENTS}

Authors would like to thank all the institution for allowing them to conduct this study and the library for looking into the information related to the topic.

Funding: No funding sources Conflict of interest: None declared
Ethical approval: The study was approved by the Institutional Ethics Committee

\section{REFERENCES}

1. Go AS, Mozaffarian D, Roger VL, American Heart Association Statistics Committee and Stroke Statistics Subcommittee et al. Heart disease and stroke statistics 2014 update: A report from the American Heart Association. Circulation. 2013;129:e28-292.

2. World Health Organization (WHO). A global brief on hypertension. Available at: http://www.who.int/cardiovascular_diseases/publication s/global_brief_hypertension/en/. Accessed on: 02-Jan2015.

3. James PA, Oparil S, Carter BL, Eighth Joint National Committee (JNC 8) Members et al. 2014 evidence-based guideline for the management of high blood pressure in adults: report from the panel members appointed to the Eighth Joint National Committee (JNC 8), Supplemental Content. JAMA. 2014;311:507-20.

4. Lim SS, Vos T, Flaxman AD, Danaei G, Shibuya K, Adair-Rohani $\mathrm{H}$, et al. A comparative risk assessment of burden of disease and injury attributable to 67 risk factors and risk factor clusters in 21 regions, 1990-2010: a systematic analysis for the Global Burden of Disease Study 2010. Lancet. 2012;380:2224-60.

5. Causes of Death. [online database]. Geneva, World Health Organization; 2008. Available at: http: //www.who.int/healthinfo/global_burden_disease/cod_2 008 _sources_methods.pdf. Accessed on 02-Jan-2015.

6. Gupta R, Gupta VP. Hypertension epidemiology in India: lessons from Jaipur Heart Watch. Current science. 2009;97(3):349-55

7. Sandozi T, Emani VK. Survey of prescription pattern of anti-hypertensive drugs in hypertensives and hypertension associated diabetics. Int $\mathbf{J}$ Pharm Bio Sci. 2010;1(4):23.

8. Joseph N, Yogananda R, Bharathi DR, Padman V, Sandeep GN. A study on prescription pattern of antihypertensive agents in chronic renal failure patients and assessment of medication adherence. Int J Pharm Sci Rev Res 2017;45(2):72-5.

9. Saju AP, Edakkarayil AC, Maheswari E, Gurudev KC. Prescribing pattern and cost effectiveness analysis of antihypertensive drugs in chronic kidney disease patients. EJPMR. 2016;3(1):219-25.

10. Bhanu PB, Basavanna PL. Pattern of antihypertensive drug utilisation among chronic kidney disease patients in a dialysis unit of a tertiary care hospital, Int $\mathbf{J}$ of Biomed Resea. 2015;6(04):251-4.

11. Elhami E, Nagaraju K. Drug utilization evaluation of antihypertensive drugs in diabetic patients with CKD. World J of Phar and Pharmaceu Scien. 2015;4(11):115966.

Cite this article as: Bharani $\mathrm{K}$, Bharani $\mathrm{R}$, Vohra R, Goyal C. Drug utilization pattern of antihypertensive drugs in chronic kidney disease stage 5 patients in a tertiary care hospital of central India. Int J Basic Clin Pharmacol 2018;7:1411-4. 